\title{
Conformational Cooling Dynamics in Matrix-Isolated 1,3-Butanediol ${ }^{\dagger}$
}

\author{
Mário T. S. Rosado, ${ }^{*},{ }^{\star}$ António J. Lopes Jesus, ${ }^{\circledR}$ Igor D. Reva, ${ }^{\ddagger}$ Rui Fausto, ${ }^{\ddagger}$ and \\ José S. Redinha \\ Department of Chemistry, University of Coimbra, 3004-535, Coimbra, Portugal, and \\ Faculty of Pharmacy, University of Coimbra, 3004-295, Coimbra, Portugal
}

Received: January 26, 2009; Revised Manuscript Received: April 3, 2009

\begin{abstract}
The complete conformational space of monomeric 1,3-butanediol has been characterized theoretically, and 73 unique stable conformers were found at the MP2/6-311++G(d,p) level. These were classified into nine families whose members share the same heavy atom backbone configurations and differ in the hydrogen atom orientations. The first and third most populated backbone families are governed by the formation of an intramolecular hydrogen bond; however, the second precludes this type of interaction and was frequently overlooked in previous studies. Its stability is determined by the relatively high entropy of its main conformers. The hydrogen bonding of four of the most important conformers was characterized by means of atoms in molecules (AIM, also known as QTAIM) and natural bond orbital (NBO) analyses. Using appropriate isodesmic reactions, hydrogen bonding energy stabilizations of $12-14 \mathrm{~kJ} \mathrm{~mol}^{-1}$ have been found. Experimentally, monomeric molecules of 1,3-butanediol were isolated in low-temperature inert matrixes, and their infrared spectra were analyzed from the viewpoint of the conformational distribution. All the relevant transition states for the conformational interconversion reaction paths were characterized at the same level of theory to interpret the conformational cooling dynamics observed in the low-temperature matrixes. The energy barriers for rotation of the $\mathrm{OH}$ groups were calculated to be very low $\left(<3 \mathrm{~kJ} \mathrm{~mol}^{-1}\right)$. These barriers were overcome in the experiments at $10 \mathrm{~K}$ (Ar matrix), in the process of matrix deposition, and population within each family was reduced to the most stable conformers. Further increase in the substrate temperature (up to $40 \mathrm{~K}$, Xe matrix) resulted in conformational cooling where the medium-height barriers $\left(\sim 13 \mathrm{~kJ} \mathrm{~mol}^{-1}\right)$ could be surmounted and all conformational population converted to the ground conformational state. Remarkably, this state turned to consist of two forms of the most stable hydrogen bonded family, which were predicted by calculations to be accidentally degenerated and were found in the annealed matrix in equal amounts. All of these experimentally observed conformational cooling processes were analyzed and supported by full agreement with the theoretical calculations.
\end{abstract}

\section{Introduction}

Butanediol positional isomers have many chemical and biochemical applications $\mathrm{s}^{1,2}$ and are a very interesting set of molecules due to their structural features. Their conformational spaces are governed by the relative importance of the steric arrangement of the carbon backbone and the possibility of formation of an intramolecular hydrogen bond (H-bond). The existence, strength, and importance of the latter is determined by the distance between the hydroxyl groups in the different molecules. ${ }^{3,4}$ Their close proximity in the vicinal isomers inhibits the H-bond formation or makes it very weak. ${ }^{5-7}$ In the case of 1,4-butanediol, the greater distance between the polar groups allows the formation of a relatively strong $\mathrm{H}$-bond, at the cost of some destabilization by a twisted $\mathrm{O}-\mathrm{C}-\mathrm{C}-\mathrm{C}-\mathrm{C}-\mathrm{O}$ backbone. ${ }^{8}$ In 1,3-butanediol, its backbone structure is expected to accommodate a relatively strong $\mathrm{H}$-bond without the conformational hindrance present in its positional isomers.

Although some theoretical ${ }^{6,9,10}$ and experimental ${ }^{10,11}$ studies have been performed on this molecule, we are not aware of a complete exploration of its conformational space. Previous

\footnotetext{
Part of the "Robert Benny Gerber Festschrift"

* Corresponding author. Phone: +351 239854471. E-mail: mtulio@ qui.uc.pt.

* Department of Chemistry.

${ }^{\S}$ Faculty of Pharmacy.
}

studies indicate that the energy differences between its conformers are quite small and that the two most stable conformers are characterized by an internal H-bond between the hydroxyl groups. ${ }^{6}$ Thus, the use of post Hartree-Fock theoretical methods, including electron correlation, such as MP2, and the use of a fairly large basis set is desirable to study this molecule. Moreover, earlier theoretical studies have previously considered only a limited number of conformers; namely, those with an H-bond. ${ }^{9}$ As will be shown in the present work, other forms without this specific interaction also play an important role in the conformational space of 1,3-butanediol.

As such, the aim of this work is to present a full characterization of the potential energy surface of the isolated 1,3-butanediol molecule at a high level of theory (using post Hartree-Fock theoretical methods, which consider the effects of the electron correlation and a fairly large basis set), assess the main factors governing the relative stability of its conformers, and study the dynamics of its conformational interconversion in low-temperature inert matrixes. This was achieved by the experimental identification of the most abundant conformers present in the low-temperature matrixes, conformational cooling effects taking place during deposition of these matrixes, ${ }^{12,13}$ and observation of rotamerization reactions upon matrix annealing, rationalizing these experimental results on the basis of the theoretically obtained potential energy surface of the molecule. 
The matrix isolation method coupled with infrared spectroscopy is a very powerful tool for characterizing the conformational composition of a molecular species. The improved resolution of the low-temperature spectra permits separation of spectral features related to different conformers, which can be accurately assigned with the help of adequate theoretical calculations because of the isolated state of the molecules in an inert matrix. The annealing of the matrix to higher temperatures can trigger conformational cooling. This occurs when the populational distribution of conformers, frozen on the cryogenic substrate from the room temperature vapor, is enriched with lower energy states if heating of the sample provides enough thermal energy to overcome the conformational interconversion barriers. Generally, this occurs only when the rotamerization barriers are low, of a few kilojoules per mole. An analogous phenomenon can also occur during deposition of the matrixes, due to the local heating of the matrix upon landing on the matrix surface of the molecules being deposited. ${ }^{12,13}$

Due to the importance of the intramolecular H-bonding in the studied molecule, ${ }^{9-11}$ a detailed analysis of this interaction was also undertaken on the basis of various theoretical and experimental approaches. Hence, both the natural bond orbital $(\mathrm{NBO})^{14,15}$ and atoms in molecules (AIM) ${ }^{16}$ theories were used in the present study. The quantification of the H-bond strengths was done theoretically by using appropriate isodesmic reactions within the molecular tailoring methodology ${ }^{17}$ and, experimentally, by measuring the bathochromic shift of the stretching vibration of the electron acceptor $\mathrm{X}-\mathrm{H}$ group and applying previously developed empirical relationships between this quantity and the H-bond energy. ${ }^{18}$

\section{Computational Methods}

1,3-Butanediol exists in two enantiomeric forms $(R$ and $S)$ about the chiral $\mathrm{C}_{3}$ atom, which have an identical conformational space for the isolated molecules. In the present study, only the $R$ form has been considered. The intramolecular dynamics in 1,3-butanediol results mainly from the presence in this molecule of four flexible coordinates associated with the rotation around two $\mathrm{C}-\mathrm{O}$ bonds and two $\mathrm{C}-\mathrm{C}$ bonds. These coordinates correspond to the four conformationally relevant dihedral angles: $\mathrm{H}_{1}-\mathrm{O}_{1}-\mathrm{C}_{1}-\mathrm{C}_{2}\left(\varphi_{1}\right), \mathrm{O}_{1}-\mathrm{C}_{1}-\mathrm{C}_{2}-\mathrm{C}_{3}\left(\varphi_{2}\right), \mathrm{C}_{1}-\mathrm{C}_{2}-\mathrm{C}_{3}-\mathrm{O}_{3}$ $\left(\varphi_{3}\right)$, and $\mathrm{C}_{2}-\mathrm{C}_{3}-\mathrm{O}_{3}-\mathrm{H}_{3}\left(\varphi_{4}\right)$. The atom numbering scheme and the four torsions are shown in Figure 1.

Within this manuscript, the conformations of 1,3-butanediol are designated by a set of four letters specifying the orientations around the $\varphi_{1}, \varphi_{2}, \varphi_{3}$, and $\varphi_{4}$ dihedrals. The letters used are $\mathrm{t}(\mathrm{T}), \mathrm{g}(\mathrm{G})$ and $\mathrm{g}^{\prime}\left(\mathrm{G}^{\prime}\right)$, specifying dihedrals around $180^{\circ},+60^{\circ}$, and $-60^{\circ}$, respectively. Capital letters are used for the two $\mathrm{C}-\mathrm{C}$ backbone torsions, and the lower case letters represent the two $\mathrm{C}-\mathrm{O}$ torsions. For example, the idealized conformation $\mathrm{tGG}^{\prime} \mathrm{g}$ would have $\left(\varphi_{1}, \varphi_{2}, \varphi_{3}, \varphi_{4}\right)=(180,60,-60,60)$.

All possible $3^{4}=81$ conformations were used as initial structures and fully optimized, with tight criteria, at the MP2 level of theory ${ }^{19-21}$ using the $6-311++\mathrm{G}(\mathrm{d}, \mathrm{p})$ basis set. ${ }^{22-24}$ Four input structures with $\mathrm{GG}^{\prime}$ backbone $\left(\mathrm{gGG}^{\prime} \mathrm{t}, \mathrm{gGG}^{\prime} \mathrm{g}^{\prime}, \mathrm{g}^{\prime} \mathrm{GG}^{\prime} \mathrm{g}\right.$, $\left.\mathrm{tGG}^{\prime} \mathrm{g}^{\prime}\right)$ and four input structures with $\mathrm{G}^{\prime} \mathrm{G}$ backbone $\left(\mathrm{g}^{\prime} \mathrm{G}^{\prime} \mathrm{Gt}\right.$, $\mathrm{g}^{\prime} \mathrm{G}^{\prime} \mathrm{Gg}, \mathrm{gG}^{\prime} \mathrm{Gg}^{\prime}, \mathrm{tG}^{\prime} \mathrm{Gg}$ ) converged to other minima within the same backbone family. The Hessian matrices of all geometries, optimized with tight criteria, were calculated at the same level to check the nature of each resulting equilibrium structure and to calculate its infrared spectrum. This also enabled the determination of thermodynamical quantities such as enthalpy, entropy, and free energy at $298.15 \mathrm{~K}$ by the usual statistical mechanics methods.
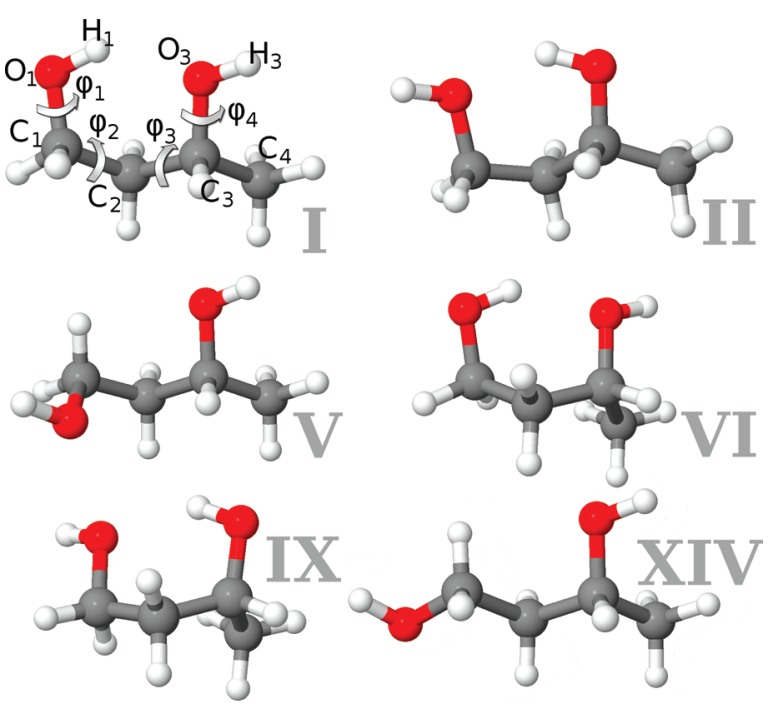

Figure 1. Optimized structures of the two most stable conformers of 1,3-butanediol (I and II) and of other conformers of the compound that are important in the context of the discussion presented in this article (V, VI, IX, and XIV). Atom numbering scheme and identification of the dihedral angles is presented in conformer I.

All relevant barriers to intramolecular rotation were calculated using the QST3 variety of the synchronous transit-guided quasiNewton (STQN) method. ${ }^{25,26}$ All transition states were characterized as first-order saddle points by the presence of one imaginary frequency, as revealed by analysis of the corresponding Hessian matrices. All calculations mentioned above were performed with the Gaussian 03 program package. ${ }^{27}$

The NBO analysis was carried out using the NBO 5.G program $^{28}$ linked to the Gamess program ${ }^{29}$ version 22-Feb-2006 (R5) and the AIM calculations were performed with the Extreme program $^{30}$ included in the Aimpac software package. ${ }^{31}$ The MP2/ $6-311++G(d, p)$ wave function corresponding to the optimized geometries was used in both NBO and AIM calculations.

\section{Experimental Section}

Commercial $(R)$-1,3-butanediol (Aldrich, > 99\%) was used in the present work. The compound was loaded into a Knudsen cell, which was connected to the vacuum system of the cryostat through an SS-4BMRG (Nupro) needle valve. Before the experiment, the compound was additionally purified from dissolved gases using pumping. During the experiment, the valve was kept at $298 \mathrm{~K}$, and this temperature defined the equilibrium ratio of butanediol conformers in the vapor. Matrix gases (argon N60 and xenon N45, supplied by Air Liquide) were deposited, without further purification, using standard manometric procedures. The samples were diluted enough (estimated concentrations of about 1:1000), since no absorptions due to aggregates were observed in the spectra.

A CsI window was used as optical substrate for the matrixes. Its temperature was stabilized at 10 and $20 \mathrm{~K}$ for argon and xenon matrixes, respectively, and measured directly at the sample holder by a silicon diode sensor connected to a digital controller (Scientific Instruments, model 9650-1), with accuracy of $0.1 \mathrm{~K}$.

The low-temperature equipment was based on a closed-cycle helium refrigerator (APD Cryogenics) with a DE-202A expander. Infrared spectra were registered with resolution of 0.5 $\mathrm{cm}^{-1}$ in the range $4000-400 \mathrm{~cm}^{-1}$ using a Mattson (Infinity 60AR Series) Fourier transform infrared spectrometer equipped with a deuterated triglycine sulfate detector and a $\mathrm{KBr}$ beam- 
TABLE 1: Dihedral Angles, Relative Energies and Boltzmann Populations at 298.15 K Calculated at the MP2/6-311++G(d,p) Level for the Conformers Belonging to the Four Most Abundant Backbone Families of (R)-1,3-Butanediol ${ }^{a}$

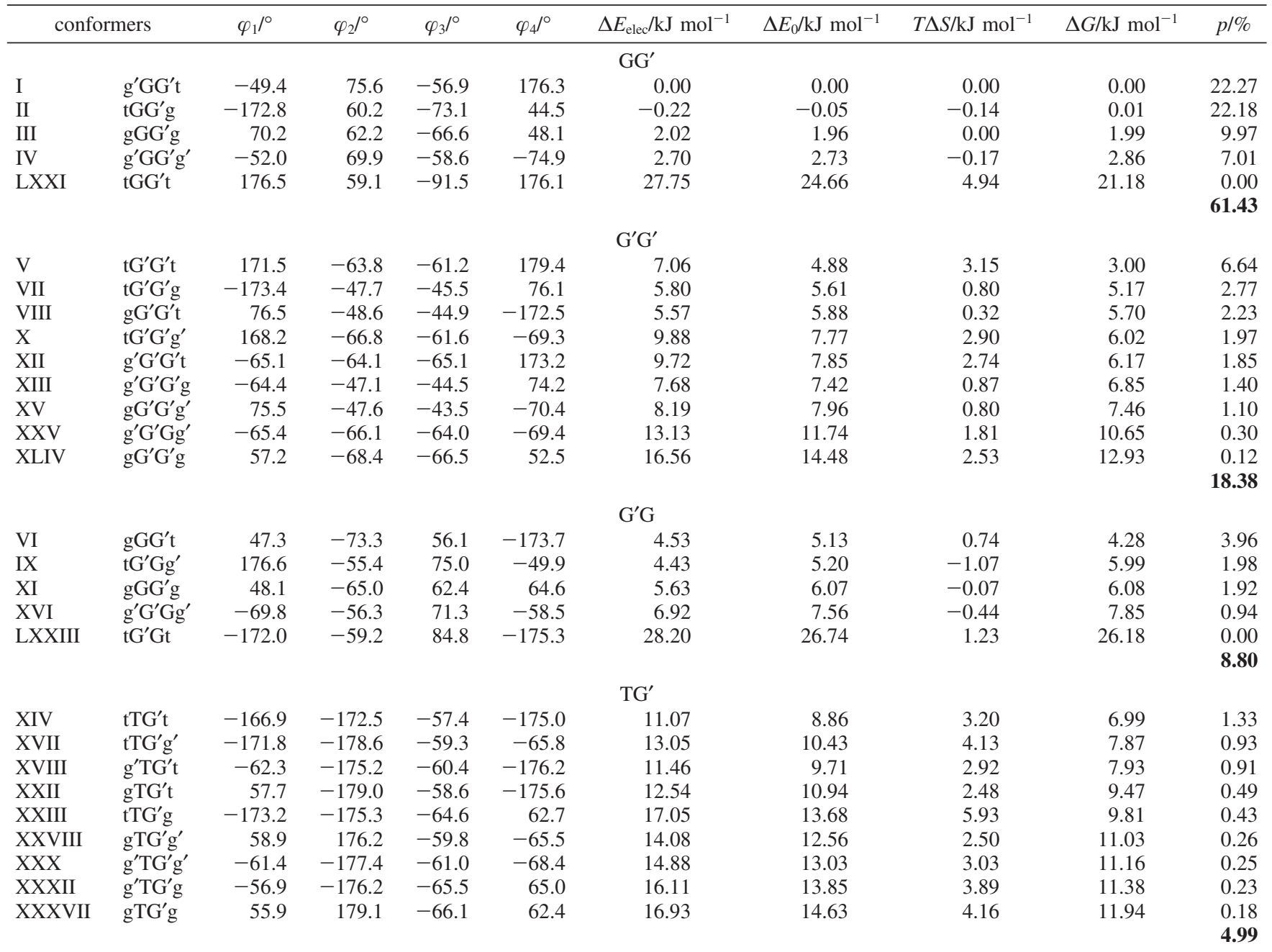

${ }^{a}$ Dihedrals: $\varphi_{1}, \mathrm{H}_{1} \mathrm{O}_{1} \mathrm{C}_{1} \mathrm{C}_{2} ; \varphi_{2}, \mathrm{O}_{1} \mathrm{C}_{1} \mathrm{C}_{2} \mathrm{C}_{3} ; \varphi_{3}, \mathrm{C}_{1} \mathrm{C}_{2} \mathrm{C}_{3} \mathrm{O}_{3} ; \varphi_{4}, \mathrm{C}_{2} \mathrm{C}_{3} \mathrm{O}_{3} \mathrm{H}_{3}$. All energy values are relative to conformer I. The Roman numbers in the first column correspond to the order of the relative Gibbs energies at $298 \mathrm{~K}$. $\Delta E_{\text {elec, }}$, electronic energy; $\Delta E_{0}$, energy at $0 \mathrm{~K}$ including zero-point vibrational energy; $T \Delta S$, entropic factor at $298 \mathrm{~K} ; \Delta G$, Gibbs energy at $298 \mathrm{~K}$; and $p$, conformational population at $298 \mathrm{~K}$. The values of $E_{\text {elec }}, E_{0}, T S$, and $G$ for conformer I (in hartree) are $-308.1215650,-307.977127,0.039128$, and -308.008 008, respectively. Bold numbers in the last column represent the total populations of each backbone family.

splitter. Modifications of the sample compartment of the spectrometer were made to couple it with the cryostat head and allow purging of the instrument by a stream of dry nitrogen to remove carbon dioxide and water vapors.

\section{Results and Discussion}

Conformational Analysis. Optimization of the 81 starting geometries resulted in 73 unique conformers. These were grouped into families, each one formed by conformers sharing the same heavy atom backbone. The five most stable families (see Table 1) account for $93 \%$ of the total room temperature population and include all individual conformers that have populations above $1 \%$. Table 1 includes the values of all relevant dihedral angles and the electronic $\left(E_{\text {elec }}\right)$ and zero-point corrected energies $\left(E_{0}\right)$ as well as the thermodynamical quantities at 298.15 $\mathrm{K}$ of the conformers belonging to the five most important families, labeled by Roman numerals designating their order of stability at room temperature. The data obtained for the conformers of all remaining backbone families are given as Supporting Information.

The most populated backbone family is $\mathrm{GG}^{\prime}$. It includes the four most stable conformers (I-IV) and represents about $61 \%$
TABLE 2: Geometrical Parameters for the Conformers of (R)-1,3-Butanediol Presenting Intramolecular Hydrogen Bonding

\begin{tabular}{ccccc}
\hline conformer & $\mathrm{O}_{\mathrm{A}}-\mathrm{H} / \AA^{a}$ & $\mathrm{O}_{\mathrm{D}} \cdots \mathrm{H} / \AA^{a}$ & $\mathrm{O}_{\mathrm{A}}-\mathrm{H} / \AA^{a}$ & $\mathrm{O}_{\mathrm{A}}-\mathrm{H} \cdots \mathrm{O} /{ }^{\circ a}$ \\
\hline I & 0.9650 & 1.98 & 0.9623 & 138.2 \\
II & 0.9657 & 1.97 & 0.9612 & 141.3 \\
III & 0.9661 & 2.03 & 0.9623 & 140.2 \\
IV & 0.9653 & 2.04 & 0.9640 & 138.0 \\
VI & 0.9648 & 1.98 & 0.9623 & 139.6 \\
IX & 0.9654 & 2.00 & 0.9612 & 138.8 \\
XI & 0.9651 & 2.06 & 0.9632 & 138.4 \\
XVI & 0.9654 & 2.11 & 0.9624 & 134.1
\end{tabular}

$a$ "D" and "A" refer to electron donor and acceptor groups.

of the overall conformational population at room temperature. This backbone structure allows the two $\mathrm{OH}$ groups to be in close proximity, thus allowing the formation of an intramolecular H-bond. As can be seen from the data shown in Table 2, the values of the geometrical parameters characterizing this type of interaction $(\mathrm{O} \cdots \mathrm{H}$ distance and $\mathrm{O}-\mathrm{H} \cdots \mathrm{O}$ angle) for the four most stable conformers are within the cutoff limits generally adopted for this type of interaction. ${ }^{32,33}$ Nevertheless, it should be noted that these cut-offs should only serve as general 
guidelines. A definitive assessment of its existence and strength should be based on more reliable methods referred to in the Introduction and used in this work.

The optimized geometries of the two most relevant conformers (I and II) are presented in Figure 1. They are practically isoenergetic and account for more than $40 \%$ of the total population at room temperature. The structure of the global minimum is in excellent agreement with that of the only conformer detected by conventional microwave spectroscopy. ${ }^{11}$ These forms differ from one another in the role played by the two $\mathrm{OH}$ groups as donors or acceptors. In conformer $\mathrm{I}$, the $\mathrm{O}_{1} \mathrm{H}_{1}$ acts as electron acceptor, and $\mathrm{O}_{3} \mathrm{H}_{3}$, as electron donor, whereas in form II, these groups act in the opposite way. Conformer II has the lowest electronic energy and enthalpy. However, at room temperature, this difference is compensated by a slightly lower entropy of II when compared to I, and ultimately, the conjugation of all thermodynamic parameters results in practically equal Gibbs free energies for these two forms $\left(\Delta G=0.01 \mathrm{~kJ} \mathrm{~mol}^{-1}\right.$; see Table 1).

The change of the electron donor $\mathrm{OH}$ group orientation from trans to gauche + or gauche-, as occurring in conformers III and IV relative to conformers II and I, respectively, gives an energy increase of about $2-3 \mathrm{~kJ} \mathrm{~mol}^{-1}$.

The very high energy of conformer LXXI is remarkable, despite belonging to the most stable backbone family. This is attributed not only to the impossibility of formation of an intramolecular H-bond but also to the strong repulsion between the oxygen lone pairs of the hydroxyl groups.

The conformational pattern exhibited by the $\mathrm{G}^{\prime} \mathrm{G}$ family is close to that of $\mathrm{GG}^{\prime}$ (see Table 1). On the basis of the values of the geometrical parameters given in Table 2, an intramolecular H-bond also exists in conformers VI, IX, XI, and XVI (Figure 1). The main structural difference between these two backbone configurations lies in the $\mathrm{C}-\mathrm{C}-\mathrm{C}-\mathrm{C}$ dihedral. Unlike the most stable $\mathrm{GG}^{\prime}$ backbone, which is characterized by a distended carbon chain, the $\mathrm{C}-\mathrm{C}-\mathrm{C}-\mathrm{C}$ dihedral is gauche - in the $\mathrm{G}^{\prime} \mathrm{G}$ family of conformers. This conformational change brings the $\mathrm{CH}_{3}$ and $\mathrm{CH}_{2} \mathrm{OH}$ groups close together in conformers such as VI and IX, leading to the establishment of steric repulsions between these groups. Comparing the energy of the $\mathrm{GG}^{\prime}$ and $\mathrm{G}^{\prime} \mathrm{G}$ forms sharing the same type of relative $\mathrm{OH}$ group orientations (VI/I, IX/II, XVI/III, XI/IV; see Figure 1), energy differences of about $3-6 \mathrm{~kJ} \mathrm{~mol}^{-1}$ can be found in each pair of conformers. These results, like that mentioned above for conformer LXXI (which is, in fact, an extreme case and has a correspondence in the LXXIII form of the $\mathrm{G}^{\prime} \mathrm{G}$ family; see Table 1), clearly show that in addition to the intramolecular H-bonding, the steric repulsions among the bulky groups are also very important in determining the relative energy of each conformer of 1,3-butanediol.

Rather surprising conformational behavior was found for the $\mathrm{G}^{\prime} \mathrm{G}^{\prime}$ family. Indeed, despite the absence of any $\mathrm{O}-\mathrm{H} \cdots \mathrm{O}$ H-bond, it represents the second-most abundant backbone structure (accounting for $\sim 18 \%$ of the overall conformational population), including the fifth-, seventh-, and eighth-most stable forms. According to the results of the thermochemical calculations included in Table 1, one can see that the major contribution for the stability of this family results from the large entropy values of forms V, X, and XII when compared with those computed for the most relevant conformers of the $\mathrm{GG}^{\prime}$ and $\mathrm{G}^{\prime} \mathrm{G}$ families. For example, conformer $\mathrm{V}$, which has a relative enthalpy of $6.1 \mathrm{~kJ} \mathrm{~mol}^{-1}$, has a Gibbs energy of only $3.0 \mathrm{~kJ}$ $\mathrm{mol}^{-1}$ above the global minimum, making it the fifth-most abundant conformer. The stabilizing role played by the entropy
TABLE 3: Electron Density $(\rho)$, Laplacian of the Electronic Density $\left(\nabla^{2} \rho\right)$, and Bonded Radius $\left(r_{H}\right.$ and $\left.r_{O}\right)$ for

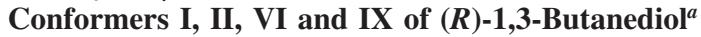

\begin{tabular}{ccccc}
\hline conformer & $\rho$ & $\nabla^{2} \rho$ & $r_{\mathrm{H}}$ & $r_{\mathrm{O}}$ \\
\hline I & 0.024066 & 0.021571 & 1.41 & 2.37 \\
II & 0.025088 & 0.023493 & 1.40 & 2.35 \\
VI & 0.017958 & 0.020252 & 1.41 & 2.34 \\
IX & 0.020908 & 0.019091 & 1.44 & 2.34
\end{tabular}

${ }^{a}$ All topological properties are given in atomic units.

in the $\mathrm{TG}^{\prime}$ family is also evident. In fact, whereas the relative enthalpy values lie between 10 and $16 \mathrm{~kJ} \mathrm{~mol}^{-1}$, those of the Gibbs energy range from 7 to $12 \mathrm{~kJ} \mathrm{~mol}^{-1}$.

Hydrogen Bonding. According to the theory of AIM, the formation of an $\mathrm{A}-\mathrm{H} \cdots \mathrm{B}$ H-bond is identified by the existence of a bond critical point $(\mathrm{BCP})$, with the $(3,-1)$ topology, and a bond path between $\mathrm{H}$ and $\mathrm{B}$ atoms. ${ }^{16}$ On the basis of the AIM formalism, Koch and Popelier proposed a set of eight criteria for the establishment of an H-bond. ${ }^{34}$ In the present study, the AIM analysis was applied to conformers I, II, VI, and IX. Some relevant topological properties are given in Table 3.

As can be seen in this Table, for all four conformers considered, a BCP was found in the $\mathrm{H} \cdots \mathrm{O}$ path. Moreover, the corresponding values of electronic density $(\rho)$ and its laplacian $\left(\nabla^{2} \rho\right)$ are within the range of values generally accepted for the establishment of an H-bond. ${ }^{35}$ The establishment of this type of interaction also requires the existence of mutual penetration between the hydrogen and electron donor oxygen. This implies that $r_{\mathrm{H}}^{0}>r_{\mathrm{H}}$ and $r_{\mathrm{O}}{ }^{0}>r_{\mathrm{O}}$, where $r^{0}$ is the nonbonded radius (estimated as distance between the nucleus and a given $\rho(\mathrm{r})$ contour, usually 0.001 au, in the H-bond direction) and $r$ is the bonded radius (distance between the nucleus and the BCP). This condition is satisfied for all conformers. The comparison of the topological properties at the BCP for the different conformers also enables evaluation of the relative strength of the H-bond. According to the values of the electron density at the $\mathrm{BCP}$, the $\mathrm{H}$-bond seems to be stronger in forms I and II and relatively weaker in IX and VI.

Within the scope of the NBO analysis, an $\mathrm{A}-\mathrm{H} \cdots \mathrm{B}$ $\mathrm{H}$-bonding is interpreted in terms of electron transfer from the lone pairs of $\mathrm{B}$ to the vacant antibond orbital of the $\mathrm{A}-\mathrm{H}$ group, $\sigma^{*}(\mathrm{~A}-\mathrm{H})$. The energy accompanying the electron delocalization between the filled bonding orbital, $\Phi_{i}$, of energy $\varepsilon_{i}$ and a vacant antibond orbital, $\Phi_{j^{*}}$, of energy $\varepsilon_{j^{*}}$ is given by ${ }^{14,36,37}$

$$
E_{i, j^{*}}{ }^{(2)}=-n_{i} \frac{\left\langle\Phi_{i}|\hat{F}| \Phi_{j^{*}}\right\rangle^{2}}{\varepsilon_{j^{*}}-\varepsilon_{i}}
$$

where $n_{i}$ is the $\Phi_{i}$ occupancy and $\hat{F}$ is the Fock operator.

The effect of an $\mathrm{H}$-bond on the participating hydrogen atom can be observed in the natural population analysis (see Table 4). The increased occupancy of the $\sigma^{*}(\mathrm{~A}-\mathrm{H})$ antibond causes the repolarization of $\sigma(\mathrm{A}-\mathrm{H})$, decreasing the electron density at the hydrogen atom. As a matter of fact, the repolarization effect overcomes the increasing occupancy of the antibonding orbital, resulting in a net decrease in the electron population at the hydrogen atom. ${ }^{8}$

The NBO analysis of the forms I, II, VI, and IX clearly reveals that all of them are stabilized by H-bonding involving both lone pairs of the alkaline oxygen atom and the $\sigma^{*}(\mathrm{O}-\mathrm{H})$ antibond orbital of the acidic oxygen (in Lewis terms). One oxygen lone pair (Lp1) has natural hybrid orbital configurations ranging from $\mathrm{sp}^{1.12}$ to $\mathrm{sp}^{1.21}$, whereas the other $(\mathrm{Lp} 2)$ has a practically pure $\mathrm{p}$ donor character in all four conformers (see 
TABLE 4: MP2/6-311++G(d,p) Characterization of the Donor-Acceptor Natural Bond Orbital Interactions Associated with Intramolecular Hydrogen Bond Formation ${ }^{a}$

\begin{tabular}{|c|c|c|c|c|c|c|c|c|}
\hline conformer & \multicolumn{2}{|c|}{ I } & & & \multicolumn{2}{|c|}{ VI } & \multicolumn{2}{|c|}{ IX } \\
\hline \multicolumn{9}{|c|}{ Interaction } \\
\hline donor & $n\left(\mathrm{Lp}_{1} \mathrm{O}_{3}\right)$ & $n\left(\mathrm{Lp}_{2} \mathrm{O}_{3}\right)$ & $n\left(\mathrm{Lp}_{1} \mathrm{O}_{1}\right)$ & $n\left(\mathrm{Lp}_{2} \mathrm{O}_{1}\right)$ & $n\left(\mathrm{Lp}_{1} \mathrm{O}_{3}\right)$ & $n\left(\mathrm{Lp}_{2} \mathrm{O}_{3}\right)$ & $n\left(\mathrm{Lp}_{1} \mathrm{O}_{3}\right)$ & $n\left(\mathrm{Lp}_{2} \mathrm{O}_{3}\right)$ \\
\hline acceptor & \multicolumn{2}{|c|}{$\sigma^{*}\left(\mathrm{O}_{1} \mathrm{H}_{1}\right)$} & \multicolumn{2}{|c|}{$\sigma^{*}\left(\mathrm{O}_{3} \mathrm{H}_{3}\right)$} & \multicolumn{2}{|c|}{$\sigma^{*}\left(\mathrm{O}_{1} \mathrm{H}_{1}\right)$} & \multicolumn{2}{|c|}{$\sigma^{*}\left(\mathrm{O}_{3} \mathrm{H}_{3}\right)$} \\
\hline \multicolumn{9}{|c|}{ Occupancy/e } \\
\hline donor & 1.98336 & 1.97062 & 1.98461 & 1.96985 & 1.98300 & 1.97016 & 1.98503 & 1.97084 \\
\hline acceptor & \multicolumn{2}{|c|}{0.01104} & & & \multicolumn{2}{|c|}{0.01127} & \multicolumn{2}{|c|}{0.01111} \\
\hline acceptor & \multicolumn{2}{|c|}{$\mathrm{sp}^{4.38}$} & \multicolumn{2}{|c|}{$\mathrm{sp}^{3.36}$} & \multicolumn{2}{|c|}{$\mathrm{sp}^{3.68}$} & \multicolumn{2}{|c|}{$\mathrm{sp}^{3.41}$} \\
\hline \multicolumn{9}{|c|}{ Hydrogen Atomic Charge/e } \\
\hline donor & \multicolumn{2}{|c|}{0.48715} & \multicolumn{2}{|c|}{0.49089} & \multicolumn{2}{|c|}{0.48737} & \multicolumn{2}{|c|}{0.48452} \\
\hline acceptor & \multicolumn{2}{|c|}{0.46451} & & & \multicolumn{2}{|c|}{0.46410} & \multicolumn{2}{|c|}{0.46743} \\
\hline \multicolumn{9}{|c|}{ Deviation of the Oxygen Hybrid Orientation $/^{\circ}$} \\
\hline
\end{tabular}

Table 4). Regarding the $n(\mathrm{Lp} 1) \rightarrow \sigma^{*}(\mathrm{O}-\mathrm{H})$ charge transfer, the values of $E_{i, j^{*}{ }^{(2)}}$ are ordered as I $<$ II $<$ VI $<$ IX; the stabilizing energy due to $n(\mathrm{Lp} 2) \rightarrow \sigma^{*}(\mathrm{O}-\mathrm{H})$ follows the opposite order. The global value of $E_{i, j *}{ }^{(2)}$ estimated per donor group varies from -4.81 in IX to -5.58 in II. The similarities in these values indicate that the $\mathrm{H}$-bond strength is similar in the considered conformers.

Other information relevant to the H-bond study can be extracted from the NBO analysis. The data presented in Table 4 show a charge increase at the hydrogen atom of the acceptor group higher than that at the atom in the donor group and that in the non-hydrogen bonded hydroxyl groups. In addition, a change in the angular properties of the natural hybrid orbital of the acceptor group is also found. The donor-acceptor interaction causes a deviation in the orientation of the hybrid orbital from the line connecting the nuclei: the A-H bond orbital tends to bend due to this type of interaction. ${ }^{14}$ This manifestation of the $\mathrm{H}$-bonding was also found for all four conformers (see Table 4).

As was mentioned above, several theoretical approaches have been used to estimate the intramolecular H-bond energy. One of the most popular methods involves the use of an appropriate isodesmic reaction. ${ }^{38}$ However, its relatively good accuracy should not overshadow its limitations. Despite conservation of the number and type of bonds, some electronic configuration changes are bound to occur. Its success is thus highly dependent on the similarity of electronic structures on each side of the reaction. In the particular case of 1,3-butanediol, the following reaction was considered:

$$
\begin{array}{r}
\mathrm{CH}_{2}(\mathrm{OH}) \mathrm{CH}_{2} \mathrm{CH}_{2} \mathrm{CH}_{3}(\mathrm{~s} 1)+\mathrm{CH}_{3} \mathrm{CH}_{2} \mathrm{CH}(\mathrm{OH}) \mathrm{CH}_{3}(\mathrm{~s} 2) \rightarrow \\
\mathrm{CH}_{2}(\mathrm{OH}) \mathrm{CH}_{2} \mathrm{CH}(\mathrm{OH}) \mathrm{CH}_{3}(\mathrm{M})+\mathrm{CH}_{3} \mathrm{CH}_{2} \mathrm{CH}_{2} \mathrm{CH}_{3}(\mathrm{~s} 3)
\end{array}
$$

The species s1, s2, and s3 were obtained by replacing the hydroxyl groups with hydrogen atoms in the optimized 1,3butanediol molecule $(\mathrm{M})$. The intramolecular H-bond energy was estimated as $E(\mathrm{M})-[E(\mathrm{~s} 1)+E(\mathrm{~s} 2)-E(\mathrm{~s} 3)]$.

In the MP2/6-311++G(d,p) energy calculations of $s 1, s 2$, and $\mathrm{s} 3$, only the coordinates involving the substituting hydrogen atoms were relaxed; all the others were kept frozen, thus excluding the contribution of their geometry rearrangement. The calculated electronic energies of these species are given as

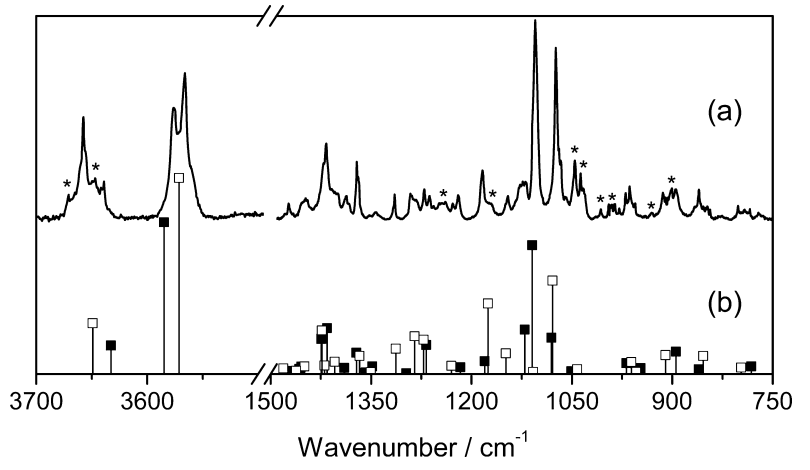

Figure 2. (a) Experimental FTIR spectrum of 1,3-butanediol monomers isolated in an argon matrix at $10 \mathrm{~K}$. (b) spectra of conformers I (ם) and II ( $\square$ ) calculated at the MP2/6-311++G(d,p) level of theory. The calculated frequencies were scaled by two factors: 0.937 for the $\mathrm{OH}$ stretching vibrations and 0.963 for all the other modes. Asterisks in trace (a) designate some of the bands that cannot be explained in terms of absorptions of conformers I or II.

Supporting Information. The estimated H-bond energies were $-14 \mathrm{~kJ} \mathrm{~mol}^{-1}$ for conformers I and II, $-13 \mathrm{~kJ} \mathrm{~mol}^{-1}$ for VI, and $-12 \mathrm{~kJ} \mathrm{~mol}^{-1}$ for IX. As far as we know, no theoretical values for the intramolecular $\mathrm{H}$-bond of this molecule are available in literature to be compared to our results. However, comparing the energies obtained for the different conformers, it can be concluded that the H-bond strengths of these are similar, a result that is in general agreement with the information obtained from AIM and NBO analysis, as well as from the structural parameters of the H-bond.

Matrix Isolation Infrared Spectra: Studies in Argon Matrix. The two most stable conformers of 1,3-butanediol (I and II, see Figure 1) are calculated to be practically isoenergetic. These two accidentally degenerate forms represent $44 \%$ of the conformational composition of the equilibrium vapor at room temperature. In principle, they should be the most abundant forms isolated in the low-temperature matrixes. Indeed, the comparison of the spectrum of a freshly deposited argon matrix (at $10 \mathrm{~K}$ ) with the spectra calculated at the MP2/6-311++G(d,p) level of theory for these conformers, shown in Figure 2, clearly confirms their presence in the sample. For example, the two bands at 3579 and $3569 \mathrm{~cm}^{-1}$ are assigned to the $\mathrm{O}-\mathrm{H}$ stretching vibrations of conformers I and II, respectively. A 

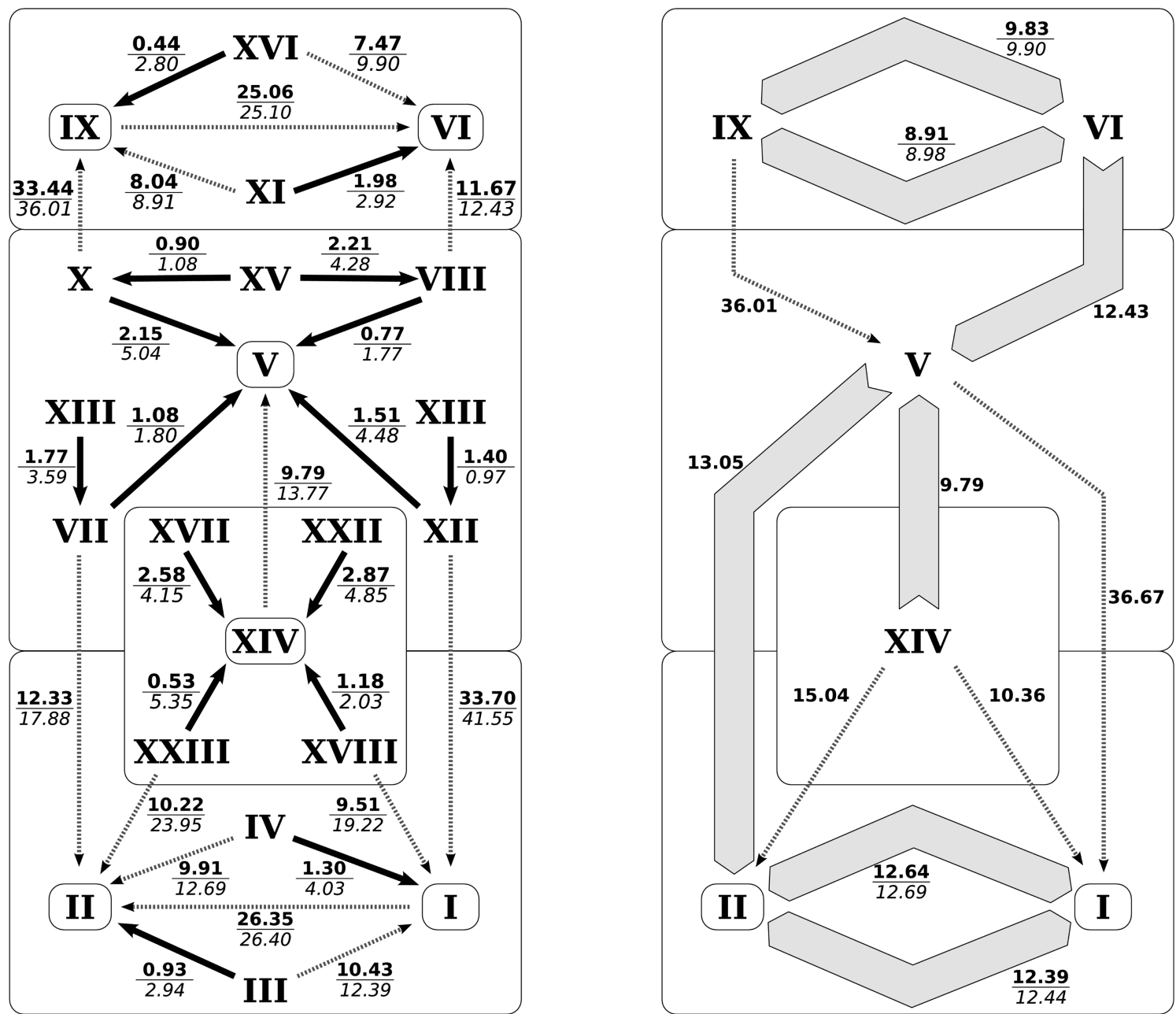

Figure 3. Left: Representation of barriers for intramolecular rotation involving the most relevant conformers of $(R)$-1,3-butanediol. Solid arrows represent barriers of less than $3 \mathrm{~kJ} \mathrm{~mol}^{-1}$ at the deposition temperature, and the dashed ones represent higher energy barriers, above $7 \mathrm{~kJ}^{\text {mol }}{ }^{-1}$. The arrows point toward the lower energy conformers at $0 \mathrm{~K}$. Top bold numbers represent the barrier heights in the arrow direction, whereas the bottom italic numbers correspond to the opposite direction. The conformers present in the argon matrix at the deposition temperature are framed. Conformers belonging to the same backbone family are grouped together inside a rounded corner rectangle. Energies are in kJ mol ${ }^{-1}$. Right: Representation of possible reaction paths during annealing of the xenon matrix, leading to equivalent populations of conformers I and II. The numbers represent the overall barrier heights across the full paths. These can include other local minima as stable intermediaries. The dashed lines represent higher energy paths with less probability.

spectroscopic manifestation of the hydrogen-bonded hydroxyl is the bathochromic shift of the $\mathrm{O}-\mathrm{H}$ stretching peak relative to the corresponding peak of the hydroxyl group not involved in the interaction $(\Delta v)$. Iogansen proposed an empirical correlation between this shift (in $\mathrm{cm}^{-1}$ ) and the H-bond enthalpy $\left(\Delta H\right.$, in kJ mol $\left.{ }^{-1}\right): \Delta H^{2}=1.92(\Delta v-40) .{ }^{18}$ According to this relationship, $\Delta H$ values of 9 and $10 \mathrm{~kJ} \mathrm{~mol}^{-1}$ were estimated for conformers I and II, respectively. These values were similar to those derived from the previous calculations and also reinforce the idea that the intramolecular H-bond has approximately the same strength in conformers I and II.

In the lower-frequency spectral region, two strong bands appear at 1109 and $1078 \mathrm{~cm}^{-1}$. Both are assigned without doubt to the $\mathrm{C}-\mathrm{O}$ stretching vibrations of the most abundant pair of conformers (I and II, respectively). Other less intense spectral features, such as those at 3672, 1049, 1040, 1010, 932, and $902 \mathrm{~cm}^{-1}$, have no correspondence in the calculated spectra of forms I and II, indicating that some other conformers should also be present in the matrix.

The results displayed in Table 1 show that conformers III-VI also contribute substantially to the room temperature conformational mixture. Nevertheless, this composition can be altered in the process of deposition in the matrix by the possible reorientation of the hydroxyl hydrogen atoms, which is characterized by very low energy barriers. This behavior has been observed in our previous studies of the other butanediol isomers. ${ }^{7,8,12}$ The conformational distribution of these molecules after deposition in the matrix was skewed toward the most stable species of each conformer family, whose members share a common heavy atom backbone. This process is generally described as conformational cooling. . $^{13,39,40}$

To obtain a better theoretical description of the observed experimental spectra and account for the effects of conformational cooling, the internal rotation barriers in 1,3-butanediol were extensively characterized. Special attention was dedicated to the four most populated families: $G^{\prime}, G^{\prime} G^{\prime}, G^{\prime} G$, and $T^{\prime}$. These barriers are shown in the left panel of Figure 3. Only the barriers corresponding to first-order transition states were considered. The arrows in Figure 3 point from a higher-energy to a lower-energy minimum. The arrows shown in bold style correspond to the low barriers (below $3 \mathrm{~kJ} \mathrm{~mol}^{-1}$ ), and all these low barriers correspond to internal rotations of the $\mathrm{OH}$ groups. The corresponding changes of geometry do not affect the heavy atom backbone; that is, occur within a given family of 
conformers. To emphasize this finding, all conformers of a given family are confined in a frame.

The conformers belonging to the $\mathrm{G}^{\prime} \mathrm{G}^{\prime}$ and $\mathrm{TG}^{\prime}$ families do not exhibit an intramolecular H-bond. Each of these two families has a clearly defined lowest energy conformer (see Table 1). These are forms $\mathrm{V}\left(\mathrm{tG}^{\prime} \mathrm{G}^{\prime} \mathrm{t}\right)$ and XIV $\left(\mathrm{tTG}^{\prime} \mathrm{t}\right)$. As expected, in both of these structures, the two conformationally relevant dihedral angles $(\mathrm{C}-\mathrm{C}-\mathrm{O}-\mathrm{H})$ assume the trans orientation. All conformers of the $\mathrm{G}^{\prime} \mathrm{G}^{\prime}$ and $\mathrm{TG}^{\prime}$ families, to be converted (directly or stepwise) to conformers $\mathrm{V}$ and XIV, correspondingly face energy barriers not higher than $3 \mathrm{~kJ} \mathrm{~mol}^{-1}$. By analogy with the other studied butanediol isomers, this implies that when monomeric 1,3-butanediol is deposited in an argon matrix at $10 \mathrm{~K}$ (the lowest possible temperature in our experimental setup), the conformational populations of the $\mathrm{G}^{\prime} \mathrm{G}^{\prime}$ and $\mathrm{TG}^{\prime}$ families should be reduced exclusively to conformers $\mathrm{V}$ and XIV, respectively.

The picture is completely different in the case of the $\mathrm{GG}^{\prime}$ and $\mathrm{G}^{\prime} \mathrm{G}$ families. As specified in the Computational Methods section, each of them is reduced to five conformers. Furthermore, conformers LXXI and LXXIII are not experimentally important, having very high relative energies and negligible populations (see Table 1). As such, in practice, each of these two families consists of four conformers. At temperatures as low as $10 \mathrm{~K}$, the relative stabilities of conformers are defined by their $\Delta E_{0}$ values. Remarkably, in both families, there are two pairs of almost equally stable conformers under these conditions. These are the nearly isoenergetic conformers I and II in family $\mathrm{GG}^{\prime}$ and the nearly isoenergetic conformers VI and XI in family $\mathrm{G}^{\prime} \mathrm{G}$. The respective calculated differences in $\Delta E_{0}$ amount to 0.05 and $0.07 \mathrm{~kJ} \mathrm{~mol}^{-1}$. In both $\mathrm{GG}^{\prime}$ and $\mathrm{G}^{\prime} \mathrm{G}$ families, the theoretical calculations predict only two pairs of low-energy barriers (below $2 \mathrm{~kJ} \mathrm{~mol}^{-1}$ ): IV $\rightarrow$ I and III $\rightarrow$ II in $\mathrm{GG}^{\prime}$ and $\mathrm{XI} \rightarrow \mathrm{VI}$ and $\mathrm{XVI}$ $\rightarrow$ IX in $\mathrm{G}^{\prime} \mathrm{G}$ (see Figure 3). The remaining barriers are much higher $\left(\sim 10 \mathrm{~kJ} \mathrm{~mol}^{-1}\right.$ or above). These findings have the following implication: if, under the actual experimental conditions (e.g., at $10 \mathrm{~K}$ ), only low barriers can be surmounted, then the conformational composition of the $\mathrm{GG}^{\prime}$ and $\mathrm{G}^{\prime} \mathrm{G}$ families will be represented by two conformers per family.

In the case of the $\mathrm{GG}^{\prime}$ family, this conclusion derived from theoretical considerations could also be immediately extracted from the experimental infrared spectra of the freshly deposited argon matrix, since the most intense peaks fit nicely the calculated spectra of these two conformers, as mentioned above. The presence in the matrix of conformers $\mathrm{V}$ and XIV is unequivocal. For example, the bands at 1050 and $902 \mathrm{~cm}^{-1}$ are easily assigned to conformer $\mathrm{V}$, and those at 1040,1010, and $932 \mathrm{~cm}^{-1}$ are attributed to conformer XIV. On the other hand, no conclusive evidence can be found at first glance for the presence or absence of conformers VI and IX in this spectrum, since most of their vibrational modes match those of forms I and II. Nevertheless, the fact that the simulated spectrum of the mixture of conformers I, II, V, VI, IX, and XIV, scaled by their predicted populations in the matrix [I $\left(\mathrm{GG}^{\prime}, 29.28 \%\right)$; II $\left(\mathrm{GG}^{\prime}, 32.15 \%\right) ; \mathrm{V}\left(\mathrm{G}^{\prime} \mathrm{G}^{\prime}, 18.38 \%\right)$; VI ( $\left.\mathrm{G}^{\prime} \mathrm{G}, 5.88 \%\right) ; \mathrm{IX}\left(\mathrm{G}^{\prime} \mathrm{G}\right.$, $2.92 \%)$; XIV ( $\left.\left.\mathrm{TG}^{\prime}, 4.99 \%\right)\right]$ is in excellent agreement with the experimental spectrum (Figure 4) points to the existence of all these forms in the matrix, as predicted theoretically.

Once identified experimentally in the spectrum of the freshly deposited argon matrix at $10 \mathrm{~K}$, the signatures of conformers I and II, and bands due to forms $\mathrm{V}$ and XIV, this matrix was subjected to annealing up to $30 \mathrm{~K}$ (at higher temperatures, the argon matrix starts to deteriorate). In the temperature interval $10-30 \mathrm{~K}$, no changes occurred in the experimental spectrum

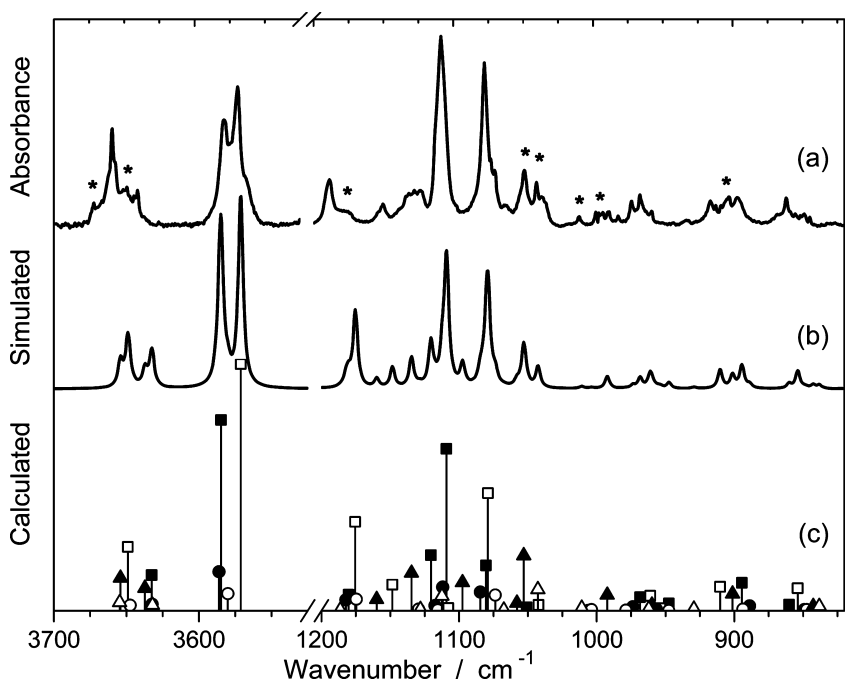

Figure 4. (a) Experimental FTIR spectrum of 1,3-butanediol monomers isolated in an argon matrix at $10 \mathrm{~K}$; (c) spectra of conformers I (ם), II $(\square)$, V $(\Delta)$, VI $(\bullet)$, IX $(\bigcirc)$ and XIV $(\Delta)$ calculated at the MP2/6$311++\mathrm{G}(\mathrm{d}, \mathrm{p})$ level of theory. The calculated frequencies were scaled by two factors: 0.937 for the $\mathrm{OH}$ stretching vibrations and 0.963 for all the other vibrations. The calculated intensities of each conformer were weighted by its expected population in the matrix at $10 \mathrm{~K}: \mathrm{I} / \mathrm{II} /$ $\mathrm{V} / \mathrm{VI} / \mathrm{IX} / \mathrm{XIV}=0.2928: 0.3215: 0.1838: 0.0588: 0.0292: 0.0499$ (see text for details). (b) Simulated spectrum of the mixture of conformers I, II, V, VI, IX and XIV. Lorentzian functions centered at the calculated frequencies with the bandwidth at half-height of $4 \mathrm{~cm}^{-1}$ were used to simulate the theoretical spectrum. The calculated frequencies and intensities were scaled as in frame (c). Asterisks designate absorptions of conformers other than I and II, which remain unchanged after annealing to $30 \mathrm{~K}$.

that could be related to conformational isomerization; the bands due to conformers V and XIV remained present. This clearly indicates that the conformational transformations related to the low-energy barriers (below $3 \mathrm{~kJ} \mathrm{~mol}^{-1}$ ) took place during matrix deposition. In addition, once the matrix is deposited, there is not sufficient thermal energy up to $30 \mathrm{~K}$ to afford conformational changes that require overcoming higher barriers, particularly changes affecting the heavy atom backbone. Juxtaposition of this experimental observation with the calculated barriers presented in Figure 3 as dashed lines leads to the conclusion that the barriers higher than $\sim 10 \mathrm{~kJ} \mathrm{~mol}^{-1}$ were insurmountable up to $30 \mathrm{~K}$.

Matrix Isolation Infrared Spectra: Studies in Xenon Matrix. One interesting question still remains open: What is the conformational ground state of 1,3-butanediol? Experiments in argon matrixes cannot answer this question, since the two most stable conformers, I and II, are separated by a barrier above $26 \mathrm{~kJ} \mathrm{~mol}^{-1}$ (directly) or above $12 \mathrm{~kJ} \mathrm{~mol}^{-1}$ (indirectly, via forms III and IV). Such barriers are insurmountable within the limits of thermal stability of argon matrixes. This conclusion follows from the fact that forms XIV and V, which are separated from the lower-energy structures by barriers of about 10 and $13 \mathrm{~kJ} \mathrm{~mol}^{-1}$ (see Figure 3) are still present in argon matrixes upon annealing to $30 \mathrm{~K}$.

Since usage of argon as the matrix host cannot afford studies for temperatures of $35 \mathrm{~K}$ and above, the choice of xenon as the matrix host allows expanding the practically available temperature range up to about $60 \mathrm{~K}$. Aiming at the possibility of experimental observation of additional conformational changes in matrixes at temperatures above $30 \mathrm{~K}, 1,3$-butanediol monomers were then isolated in a xenon matrix. The spectrum recorded immediately after deposition at $20 \mathrm{~K}$ evidences the 
presence of the same backbone families that were found to be present in the argon matrix, in particular, of forms V and XIV. The summary of this conformational composition is presented in the right panel of Figure 3. It shows only the six most stable forms of the four most important conformational families. This figure also shows various reaction paths between these forms, all of them with activation energies of about $9 \mathrm{~kJ} \mathrm{~mol}^{-1}$ or higher. The lowest energy paths (leading to lower energy conformers or between practically isoenergetic forms) are shown by thick arrows. These energy paths may represent a direct transformation (such as between forms XIV and V) or involve intermediates (that are specified in the left panel at the spots where the arrows bend).

The studies in xenon matrixes were then performed to seek for conformational rearrangements across different backbone families or within the $\mathrm{GG}^{\prime}$ and $\mathrm{G}^{\prime} \mathrm{G}$ families, which could not be observed in the studies performed in argon matrixes. After deposition of the matrix, the sample was incrementally annealed in steps of $5 \mathrm{~K}$. The two bands between 1046.5 and $1033 \mathrm{~cm}^{-1}$ (that are characteristic of forms V and XIV, respectively) started to disappear at $35 \mathrm{~K}$ and vanished when the sample temperature was $40 \mathrm{~K}$ (see Figure 5). At the latter temperature, the xenon matrix maintains sufficient rigidity, so all observed transformations should occur at the monomeric level (molecular interassociation can be neglected). Since form V can only be depopulated in favor of a more stable species (in this case, forms I or II), this allows for a direct conclusion: under the present experimental conditions (xenon matrix, $40 \mathrm{~K}$ ), barriers of about $13 \mathrm{~kJ} \mathrm{~mol}^{-1}$ (see Figure 3) can be efficiently surmounted. Therefore, all processes that require this activation energy (or less) should be allowed in the xenon matrix at $40 \mathrm{~K}$. In addition, these processes must lead toward the stabilization of the system, and the final populations should converge to the Boltzmann distribution at $40 \mathrm{~K}$.

This is an important conclusion, with the following consequences: (i) Forms IX and VI are approximately isoenergetic at $10 \mathrm{~K}$ and can be transformed into each other via forms XVI and XI with barriers of $\sim 10$ and $8 \mathrm{~kJ} \mathrm{~mol}^{-1}$, respectively. (ii) Form VI should be depopulated toward form V (via form VIII), since the barrier for this rearrangement is no higher than 12.5 $\mathrm{kJ} \mathrm{mol}^{-1}$ in that direction. Since form IX is in equilibrium with VI, it should be depopulated to form V as well (via VI). (iii) Form XIV can be depopulated to form I via XVIII (barrier $<10.4$ $\mathrm{kJ} \mathrm{mol}^{-1}$ ) or, again, to form $\mathrm{V}$ directly (barrier: $9.8 \mathrm{~kJ} \mathrm{~mol}^{-1}$ ). Form $\mathrm{V}$ is thus a key species that acts as a rotamerization intermediate for all other higher energy forms to decay. (iv) In turn, form $\mathrm{V}$ can also be consumed during annealing (in favor of form II; see Figure 3). (v) Very likely, the five high-energy conformational families (that, as already mentioned, account for only $6.4 \%$ of the total population) should also face barriers of $\sim 13 \mathrm{~kJ} \mathrm{~mol}^{-1}$ or less and eventually convert to the most stable family (forms I or II), too.

After all other conformers initially present in the gas phase have been converted to the most stable conformers I and II upon annealing to $40 \mathrm{~K}$, it is interesting to address the possibility of mutual transformation between forms I and II, which is the key issue to the identification of the ground conformational state of 1,3-butanediol. The theoretically predicted barriers for such transformations range between 12.3 (via form III) and 12.7 (via form IV) $\mathrm{kJ} \mathrm{mol}^{-1}$ (see Figure 3). Therefore, these barriers are thermally accessible at $40 \mathrm{~K}$, and a true thermodynamic equilibrium should be established between these forms in a xenon matrix. If one of these two forms would be slightly more stable than the other, the equilibrium should be shifted toward
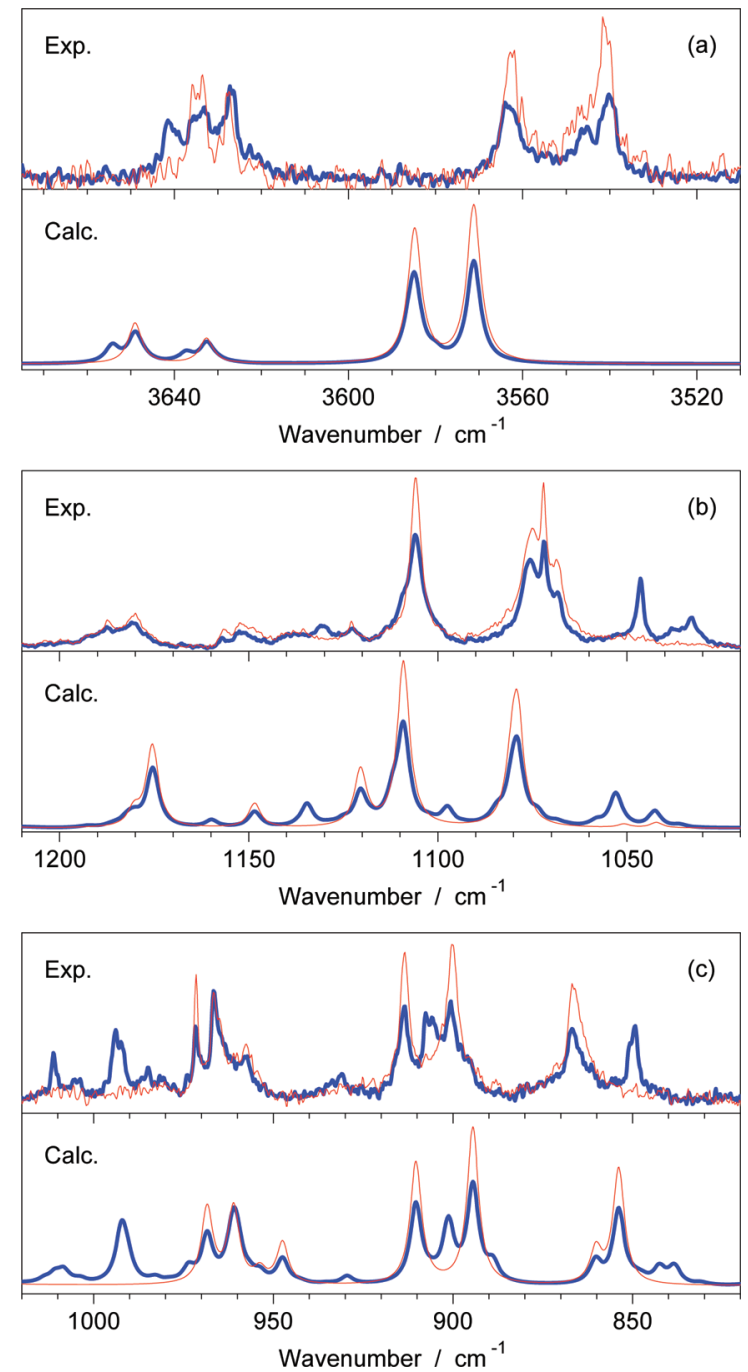

Figure 5. "Exp.": experimental FTIR spectra of 1,3-butanediol isolated in a xenon matrix at the deposition temperature, $20 \mathrm{~K}$ (bold blue line) and after annealing at $40 \mathrm{~K}$ (thin red line). "Calc.": theoretical spectra of the conformational mixture expected to be trapped in the xenon matrix at $20 \mathrm{~K}$ (bold blue line) and after annealing at $40 \mathrm{~K}$ (thin red line). In the latter case, the simulated spectrum consists of two forms only (I and II) in a 1:1 ratio. Band shapes and scaling factors for the simulation were used the same as described in Figure 4(b).

the former. To determine the conformational composition of the annealed xenon matrix, a series of theoretical simulations of the infrared spectrum of a mixture of forms I and II was then attempted, in which the relative populations of these conformers were varied. The best match between the experimental and simulated spectra was obtained where forms I and II contribute in a 1:1 ratio to the simulated spectrum (Figure 5). ${ }^{41}$ This is clear evidence that forms I and II are, indeed, truly isoenergetic, as predicted by the MP2 calculations. Additional experiments were attempted to depopulate one of the forms (I or II) by recooling the matrix to temperatures of about $10 \mathrm{~K}$, which required just a small energy difference between the two species. In the experiment, no redistribution of intensities occurred upon cooling the sample. However, we attribute this absence of changes not to the very small gap between the energies of forms I and II, but rather, to a barrier above $12 \mathrm{~kJ}$ $\mathrm{mol}^{-1}$, which turns out to be insurmountable at temperatures as low as $10 \mathrm{~K}$. This observation indicates that not only the relative conformational energies but also the barriers to conformational interconversions appear to be well-predicted by the MP2 calculations. 


\section{Conclusions}

For the first time, the complete conformational space of monomeric 1,3-butanediol has been characterized at the MP2/ $6-311++G(d, p)$ level of theory. These results reveal that (i) the gas phase conformational equilibrium is dominated by conformers belonging to the $\mathrm{GG}^{\prime}(61 \%), \mathrm{G}^{\prime} \mathrm{G}^{\prime}(18 \%)$, and $\mathrm{G}^{\prime} \mathrm{G}$ (9\%) backbone families; (ii) the stabilities of the $\mathrm{GG}^{\prime}$ and $\mathrm{G}^{\prime} \mathrm{G}$ families are mainly governed by the formation of an intramolecular H-bond, whereas that of the $\mathrm{G}^{\prime} \mathrm{G}^{\prime}$ family is determined by the relatively high entropy of its main conformers.

By AIM analysis, a critical point of type $(3,-1)$ in the $\mathrm{O} \cdots \mathrm{H}$ bond path was identified in all representative conformers prone to establish an intramolecular H-bond. The relevance of this interaction was also confirmed by NBO analysis, showing significant stabilizing energy arising from the $n(\mathrm{Lp}) \rightarrow \sigma^{*}(\mathrm{OH})$ charge transfer. The AIM and NBO analyses and geometrical data obtained for those conformers led to the conclusion that no significant differences in intramolecular H-bond strength exist among them. This agrees with the narrow range of values for the $\mathrm{H}$-bond energies obtained using isodesmic reactions (12-14 $\mathrm{kJ} \mathrm{mol}^{-1}$ ) and from the application of an empirical equation to the spectroscopic data.

In agreement with the low calculated energy barriers for rotation of the hydroxyl groups (below $3 \mathrm{~kJ} \mathrm{~mol}^{-1}$ ), isolation of 1,3-butanediol monomers in low-temperature inert matrixes led to the reduction of the number of conformers present in the gas phase equilibrium to only the most stable conformers within each family. Spectral features assigned to forms I, II, V, and XIV were observed in the experimental spectra obtained after deposition.

Annealing of the xenon matrix to $40 \mathrm{~K}$ resulted in further conformational cooling, where the medium-height barriers of about $13 \mathrm{~kJ} \mathrm{~mol}^{-1}$ could be surmounted, leading to depopulation of all high-energy forms into the ground conformational state. Remarkably, this state turned out to be composed of two forms of the $\mathrm{GG}^{\prime}$ family, I ( $\mathrm{g}^{\prime} \mathrm{GG}^{\prime} \mathrm{t}$ ) and II ( $\left.\mathrm{tGG}^{\prime} \mathrm{g}\right)$, which were found in the annealed matrix in equal amounts, in agreement with the theoretical calculations, which predicted these two conformers to be accidentally degenerated.

Note Added after ASAP Publication. This Article was published ASAP on April 23, 2009. Due to production error, additional changes were needed throughout the paper. The corrected version was reposted on April 30, 2009.

Supporting Information Available: Relative energies and Boltzmann populations at $298.15 \mathrm{~K}$ for the conformers of the least important backbone families of $(R)$-1,3-butanediol and the structure of other conformers that are important in the context of the discussion presented in this article. This material is available free of charge via the Internet at http://pubs.acs.org.

\section{References and Notes}

(1) Boutron, P. Cryobiology 1992, 29, 347.

(2) Mehl, P.; Boutron, P. Cryobiology 1988, 25, 44.

(3) Jesus, A. J. L.; Rosado, M. T. S.; Leitão, M. L. P.; Redinha, J. S. J. Phys. Chem. A 2003, 107, 3891.

(4) Fishman, E.; Chen, T. L. Spectrochim. Acta, Part A 1969, 25, 1231.

(5) Crittenden, D. L.; Thompson, K. C.; Jordan, M. J. T. J. Phys. Chem. A 2005, 109, 2971.

(6) Klein, R. A. J. Comput. Chem. 2002, 23, 585.

(7) Jesus, A. J. L.; Rosado, M. T. S.; Reva, I.; Fausto, R.; Eusébio, M. E.; Redinha, J. S. J. Phys. Chem. A 2006, 110, 4169.
(8) Jesus, A. J. L.; Rosado, M. T. S.; Reva, I.; Fausto, R.; Eusébio, M. E.; Redinha, J. S. J. Phys. Chem. A 2008, 112, 4669.

(9) Zhou, Z.; Zhang, H.; Shi, Y. J. Phys. Chem. A 2004, 108, 6520.

(10) Yi, N.; XiaoMing, D.; HaiYing, Z.; GuangZhong, Y.; Yoshinori, Y.; Yukihiro, O. Sci. China, Ser. B: Chem. 2007, 50, 23.

(11) Caminati, W.; Corbelli, G. J. Mol. Struct. 1982, 78, 197.

(12) Reva, I.; Jesus, A. J. L.; Rosado, M. T. S.; Fausto, R.; Eusébio, M. E.; Redinha, J. S. PhysChemChemPhys 2006, 8, 5339.

(13) Reva, I. D.; Stepanian, S. G.; Adamowicz, L.; Fausto, R. Chem. Phys. Lett. 2003, 374, 631.

(14) Weinhold, F.; Landis, C. R. Valency and bonding: A Natural Bond Orbital Donor-Acceptor Perspective; Cambridge University Press: New York, 2005.

(15) Klein, R. A. Chem. Phys. Lett. 2006, 429, 633.

(16) Bader, R. F. W., Atoms in molecules - a quantum theory; University Press: Oxford, 1990

(17) Deshmukh, M. M.; Gadre, S. R.; Bartolotti, L. J. J. Phys Chem. A 2006, 110, 12519 .

(18) Iogansen, A. V. Spectrochim. Acta, Part A 1999, 55, 1585.

(19) Frisch, M. J.; Head-Gordon, M.; Pople, J. A. Chem. Phys. Lett. 1990, 166, 275.

(20) Frisch, M. J.; Head-Gordon, M.; Pople, J. A. Chem. Phys. Lett. 1990, 166, 281.

(21) Head-Gordon, M.; Head-Gordon, T. Chem. Phys. Lett. 1994, 220, 122 .

(22) Krishnan, R.; Binkley, J. S.; Seeger, R.; Pople, J. A. J. Chem. Phys. 1980, 72,650 .

(23) McLean, A. D.; Chandler, G. S. J. Chem. Phys. 1980, 72, 5639.

(24) Frisch, M. J.; Pople, J. A.; Binkley, J. S. J. Chem. Phys. 1984, 80, 3265 .

(25) Peng, C. Y.; Schlegel, H. B. Isr. J. Chem. 1993, 33, 449.

(26) Peng, C. Y.; Ayala, P. Y.; Schlegel, H. B.; Frisch, M. J. J. Comput. Chem. 1996, 17, 49.

(27) Frisch, M. J.; Trucks, G. W.; Schlegel, H. B.; Scuseria, G. E.; Robb, M. A.; Cheeseman, J. R.; Montgomery, J. A., Jr.; Vreven, T.; Kudin, K. N.; Burant, J. C.; Millam, J. M.; Iyengar, S. S.; Tomasi, J.; Barone, V.; Mennucci, B.; Cossi, M.; Scalmani, G.; Rega, N.; Petersson, G. A.; Nakatsuji, H.; Hada, M.; Ehara, M.; Toyota, K.; Fukuda, R.; Hasegawa, J.; Ishida, M.; Nakajima, T.; Honda, Y.; Kitao, O.; Nakai, H.; Klene, M.; Li, X.; Knox, J. E.; Hratchian, H. P.; Cross, J. B.; Bakken, V.; Adamo, C.; Jaramillo, J.; Gomperts, R.; Stratmann, R. E.; Yazyev, O.; Austin, A. J.; Cammi, R.; Pomelli, C.; Ochterski, J. W.; Ayala, P. Y.; Morokuma, K.; Voth, G. A.; Salvador, P.; Dannenberg, J. J.; Zakrzewski, V. G.; Dapprich, S.; Daniels, A. D.; Strain, M. C.; Farkas, O.; Malick, D. K.; Rabuck, A. D.; Raghavachari, K.; Foresman, J. B.; Ortiz, J. V.; Cui, Q.; Baboul, A. G.; Clifford, S.; Cioslowski, J.; Stefanov, B. B.; Liu, G.; Liashenko, A.; Piskorz, P.; Komaromi, I.; Martin, R. L.; Fox, D. J.; Keith, T.; Al Laham, M. A.; Peng, C. Y.; Nanayakkara, A.; Challacombe, M.; Gill, P. M. W.; Johnson, B.; Chen, W.; Wong, M. W.; Gonzalez, C.; Pople, J. A. Gaussian03; Gaussian, Inc.: Wallingford, CT, 2004.

(28) Weinhold, F., NBO 5.0 program manual; Theoretical Chemistry Institute, University of Wisconsin, Madison: Madison, WI, 2001.

(29) Schmidt, M.; Baldridge, K.; Boatz, J.; Elbert, S.; Gordon, M.; Jensen, J.; Koseki, S.; Matsunaga, N.; Nguyen, K.; Su, S.; Windus, T.; Dupuis, M.; Montgomery, J. J. Comput. Chem. 1993, 14, 1347.

(30) Biegler-König, F. W.; Bader, R. F. W.; Tang, W. J. Comput. Chem. 1982, 3, 317.

(31) Bader, R. F. W. Aimpac; McMaster University: Hamilton, Ontario, Canada, 1991.

(32) Steiner, T. Angew. Chem., Int. Ed. 2002, 41, 48.

(33) Jeffrey, G. A., An Introduction to Hydrogen Bonding; Oxford University Press: Oxford, 2002.

(34) Koch, U.; Popelier, P. L. A. J. Phys. Chem. 1995, 99, 9747.

(35) Pacios, L. F.; Gómez, P. C. J. Comput. Chem. 2001, 22, 702.

(36) Weinhold, F.; Landis, C. R. Chem. Educ.: Res. Pract. Eur. 2001, 2,91 .

(37) Reed, A.; Curtiss, L.; Weinhold, F. Chem. Rev. 1988, 88, 899.

(38) Deshmukh, M. M.; Gadre, S. R.; Bartolotti, L. J. J. Phys. Chem. A 2007, 111, 10885.

(39) Barnes, A. J. J. Mol. Struct. 1984, 113, 161.

(40) Felder, P.; Günthard, H. H. Chem. Phys. 1982, 71, 9.

(41) Should the energy difference between two forms be as large as $0.23 \mathrm{~kJ} \mathrm{~mol}^{-1}$, then their equilibrium populations at $40 \mathrm{~K}$ would relate as $2: 1$, and this ratio would be reliably distinguishable in the experiment from the 1:1 ratio. This emphasizes the degree of exactness of the present MP2 calculations, validated by the agreement of the simulated 1:1 ratio with the experimental spectrum.

JP900771G 